Journal of Research in Interprofessional

Practice and

Education

Vol. 3.2

August, 2013
Journal of Research in Interprofessional Practice and Education (JRIPE)

Vol. 3.2

(C) 2013

Corresponding Author: Susanne Heiwe. Email: isusanne.heiwe@ki.sei

\section{Outcomes of a Multiprofessional Educational Intervention in Evidence-Based Practice}

\author{
Susanne Heiwe, PhD, RPT; Eva Johansson, Associate Professor, RN; \\ Kerstin Nilsson-Kajermo, PhD, RN; Karin Säflund, PhD, MSW; \\ \& Ann Ödlund Olin, PhD, RN
}

\begin{abstract}
Background: Education is a commonly used intervention in the development of evidence-based practice (EBP). The aim of this study was to evaluate the outcome of an educational intervention on healthcare professionals' perceived skills in finding, reviewing, and using research evidence in clinical practice. A further aim was to identify potential determinants for the outcome.
\end{abstract}

Methods and Findings: A three-day course in EBP was designed for registered nurses, medical social workers, physiotherapists, occupational therapists, and dieticians. The Developing Evidence-Based Practice Questionnaire (DEBP) questionnaire was administered before and six months after the intervention $(N=$ 274). Non-parametric statistics were used. The results showed an overall effect on ability to find research evidence $(p=.0005)$ and ability to review research evidence $(p=.0005)$, whereas there was no overall effect on use of research evidence in clinical practice $(p=.18)$. However, some subgroups showed a significant improvement over time, for example, those whose profession was nursing or midwifery and those who had limited experience using evidence-based practice prior to the educational intervention.

Conclusions: The results showed that a three-day course in EBP improved the participants' ability to find and review research evidence, but it did not have an overall effect on the use of research evidence in clinical practice.

Keywords: Evidence-based practice; Multiprofessional education; General equation estimation

\section{Background}

Ensuring patients receive safe, high quality care is a major goal for the healthcare system. To accomplish this goal, it is necessary to use a systematic approach in clinical practice that takes into consideration current evidence-based knowledge.

Evidence-based medicine is defined as "the conscientious, explicit, and judicious use of current best evidence in making decisions about the care of individual patients. The practice of evidence-based medicine means integrating individual clinical expertise with the best available external clinical evidence from systematic research" [1, pp. 3-5]. Since the concept and practice of evidence-based medicine was introduced in the early 1990s, the demand for evidence-based professional practice has spread from physicians to other professional groups. Today, the overarching terms evidence-based healthcare and evidence-based practice are used, which include all disciplines and areas of practice. In this article, we have chosen to focus on evidence-based practice, which can be described as a process that consists of several steps: defining the problem, asking answerable questions, finding the evidence, appraising the evidence, integrating the evidence with clinical expertise and the patient's unique circumstances, and evaluating patient outcomes [2]. 
Multi-professional intervention in EBP

Heiwe, Johansson, Nilsson-Kajermo, Säflund, \& Ödlund Olin

Journal of Research in Interprofessional Practice and Education

Vol. 3.2

August, 2013

Education is a commonly used strategy for implementing evidence-based practice within clinical practice. Prior educational efforts and studies investigating effects of teaching evidence-based practice have been particularly focused on physicians. From these studies, it is evident that education in critical appraisal skills increases participants' knowledge of evidence-based practice [3-6]. If this kind of education is integrated within clinical practice, it is possible that such an approach might, besides having an effect on knowledge and skills, also be able to support a behavioural and attitudinal change concerning the use of evidence-based practice $[7,8]$.

The concept of evidence-based practice has recently been introduced within other healthcare professional groups, such as nurses, medical social workers, physiotherapists, occupational therapists, and dietitians. Consequently, there are sparse data on the effects of education in evidence-based practice concerning these professions. Multiple healthcare situations need greater interprofessional collaboration and communication, such as interventions aiming to enhance patient safety. Interprofessional education has the explicit goal to increase collaboration and communication. It differs from most traditional continuing education in that knowledge is largely socially created through interactions with others and involves unique collaborative skills and attitudes [9]. Interprofessional education has been shown to improve quality of patient care [10].

The aim of this study was, therefore, to evaluate the outcome of an educational intervention on healthcare professionals perceived skills in finding, reviewing, and using research evidence in clinical practice. A further aim was to identify potential determinants for the outcome.

\section{Material and methods}

\section{Design}

This study had a pre-experimental design, including a one-group pretest-posttest design.

\section{Participants}

Healthcare staff at a university hospital in Sweden was invited to attend a course on evidence-based practice. The invitations were sent by email to chief managers, who distributed the invitations to the staff. The course invitation was also announced on the hospital's intranet.

In total, 274 healthcare personnel took part in the courses. Of those, 264 participants answered the Developing Evidence-Based Practice Questionnaire (DEBP) before the course, and 194 (73\%) also responded
Figure 1

\section{Flow chart of data collection}

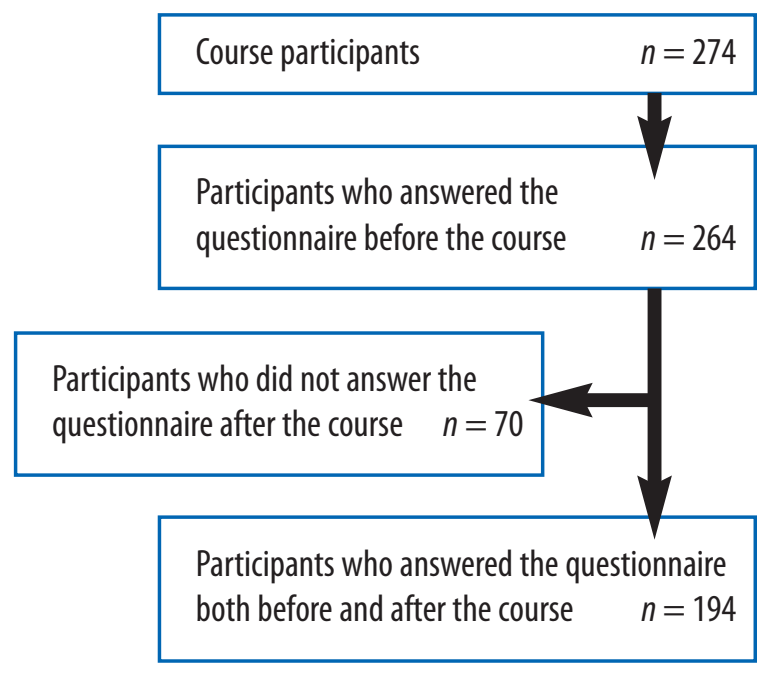


JRIPE

3

Multi-professional intervention in EBP

Heiwe, Johansson, Nilsson-Kajermo, Säflund, \& Ödlund Olin

Journal of Research in Interprofessional Practice and Education

Vol. 3.2

August, 2013
Journal of Research in Interprofessional Practice and Education

six months after the educational intervention (Figure 1). Demographic data are presented in Table 1.

Table 1

\section{Characteristics of participants}

\begin{tabular}{|l|l|l|l|l|}
\hline & $\begin{array}{l}\text { Baseline } \\
\boldsymbol{n = 2 6 4}\end{array}$ & $\begin{array}{l}\text { Follow-up } \\
\boldsymbol{n = 1 9 4}\end{array}$ & $\begin{array}{l}\text { Drop-outs } \\
\boldsymbol{n = 7 0}\end{array}$ & $\begin{array}{l}\boldsymbol{p}= \\
\text { value }\end{array}$ \\
\hline Age, years, mean (SD) & $42.4(9.0)$ & $42.6(9.2)$ & $41.7(8.6)$ & 0.49 \\
\hline Gender M/F, $n$ (\%) & $10(3.8) / 254(96.2)$ & $8(4.1) / 186(95.9)$ & $68(97.1) / 2(2.9)$ & 0.48 \\
\hline Profession, $\boldsymbol{n}(\%)$ & \multicolumn{5}{|l|}{} \\
\hline Registered nurses & $180(68.2)$ & $130(67)$ & $52(19)$ & \\
\hline Occupational therapist & $10(3.8)$ & $7(3.6)$ & $3(4.3)$ & \\
\hline Physiotherapist & $26(9.8)$ & $20(10.3)$ & $6(8.6)$ & \\
\hline Dietitian & $21(8)$ & $18(9.3)$ & $3(4.3)$ & \\
\hline Medical Social worker & $22(8.3)$ & $14(7.2)$ & $8(11.4)$ & \\
\hline Speech therapist & $3(1.1)$ & $3(1.5)$ & & \\
\hline Psychologist & $2(0.8)$ & $2(1.0)$ & & \\
\hline Academic degree, $\boldsymbol{n}(\%)$ & & & $25(35.7)$ & \\
\hline Bachelor's degree & $101(38.3)$ & $76(39.2)$ & $9(12.9)$ & \\
\hline Master's degree & $52(19.7)$ & $43(22.2)$ & $8(4.1)$ & \\
\hline Doctor's degree & $9(3.4)$ & $(1.4)$ & \\
\hline
\end{tabular}

\section{Educational intervention}

The courses were held between 2005 and 2008. The educational intervention consisted of a three-day course on evidence-based practice and was designed for registered nurses, midwives, allied professionals, and other healthcare professionals. The aim of the course was to increase the participants' basic knowledge within evidencebased practice. Prior to the start of the course, the participants received literature to read for preparation. The course content followed the evidence process and included the following components: concepts used in evidence-based practice, identifying problems in daily clinical practice, learning to create questions that can be used to find evidence-based information, searching and finding relevant evidence, appraising and interpreting evidence, and implementing evidence. Each participant was asked to identify a clinically relevant topic where he/she perceived a lack of knowledge regarding healthcare interventions that were of particular interest to him/her in relation to his/her setting. One day was allocated to select the most appropriate databases to find articles for the chosen questions and to run database searches, which were facilitated by a librarian. Teaching methods included lectures mixed with training sessions in small groups that were carried out by two healthcare professionals with a $\mathrm{PhD}$ qualification, all experienced in evidence-based practice. 
4

Multi-professional intervention in EBP

Heiwe, Johansson, Nilsson-Kajermo, Säflund, \& Ödlund Olin

Journal of Research in Interprofessional Practice and Education

Vol. 3.2

August, 2013

\section{Data collection}

Permission was obtained from Kate Gerrish to use her DEBP questionnaire [11]. It measures factors influencing the development of evidence-based practice among clinical nurses. The questionnaire was translated to Swedish by a professional bilingual translator and slightly modified to fit into a Swedish healthcare context. Two questions were omitted and two were adjusted to make it relevant for additional professions beyond nursing. In the Swedish version, the questionnaire consisted of five sections with 47 items in total, and each item had a 5-point Lickert scale. Section 1 included 21 items about sources of knowledge. Section 2 included ten items about barriers to finding and reviewing research reports and organizational information. Section 3 included five items about barriers to changing practice. Section 4 included three items about support to change practice. Section 5 included eight items about skills in finding and reviewing evidence. Demographic data were also collected. The questionnaire was administered, at baseline and six months after the intervention, to all participants who had attended all three course days. Reminders were sent twice to non-responders. Primary outcomes in this study were perceived skills in finding research evidence (item 42), reviewing research evidence (item 46) and using research evidence to change practice (item 48).

\section{Ethical considerations}

No formal approval by an ethics committee was required, according to the Swedish Act concerning the Ethical Review of Research Involving Humans. Oral and written information was given to all participants about the aim of the study and that participation was voluntary. Confidentiality was guaranteed.

\section{Statistics}

Cronbach's alpha was calculated to analyze the internal consistency of each section in the DEBP questionnaire. A Cronbach's alpha level equal to or greater than .70 was considered adequate [12]. Age is presented as mean (standard deviation [SD]), and all other demographic factors as frequencies (percentages). Differences at baseline between participants and drop-outs were tested with Mann-Whitney $U$-test. Differences between groups (e.g., professions) were tested using Fisher's test or $\mathrm{Chi}^{2}$ test.

Associations between 3 dependent factors and 12 independent factors were studied by time-lagged generalized estimation equations (GEE). GEEs were developed to extend the generalized linear models and to accommodate correlated data. It is a useful approach for repeated measurements analysis of ordered categorical outcomes where it can identify possible determinants for the dependent variables. We examined whether repeated measurement of the independent factors (basing practice knowledge on articles published in research journals [item 18], not knowing how to find appropriate research reports [item 22], not having sufficient time to find research reports [item 24], finding it difficult to understand research reports [item $28]$ ), and the following negvariables (time before-after the course, age, profession, academic degree, professional experience, work condition, and baseline rating) could predict the 3 dependent factors (finding research evidence [item 42], reviewing 


\section{JRIPE}

5

Multi-professional intervention in EBP

Heiwe, Johansson, Nilsson-Kajermo, Säflund, \& Ödlund Olin

Journal of Research in Interprofessional Practice and Education

Vol. 3.2

August, 2013 research evidence [item 46], and using research evidence to change practice [item 48]) reported repeatedly 6 months later. Items 18, 22, 24, and 28 were categorized into three response alternatives before the analysis. Possible interaction effects between the independent factors were also assessed.

Data were analysed using SPSS (15.0 for Windows) and PROC GENMOD in SAS (System 9.1). A probability value of $p<.05$ was considered to indicate a significant difference.

\section{Results}

The internal consistency of the DEBP sections was found to be high (Cronbach's $\alpha=.70$ to .87 ), except section three, which had an acceptable Cronbach's alpha (.66).

The participants answering the DEBP questionnaire both before and after the educational intervention had a mean age of $43 \pm 9$ years. The majority were registered nurses or midwives, and 39\% of the participants held a bachelor's degree. The mean professional experience was $17 \pm 10$ years, and $77 \%$ worked full time. Ninetysix percent of the participants were women. There were significantly more participants working full time of those responding to the questionnaire both before and after the intervention compared with those responding only before the intervention. Otherwise, there were no significant differences (Table 1). Descriptive data concerning primary outcomes and independent factors are presented in Table 2.

Table 2

Primary outcome items and independent factors

\begin{tabular}{|c|c|c|c|}
\hline Item & $\begin{array}{l}\text { Baseline } \\
\text { median } \\
\text { (range) }\end{array}$ & $\begin{array}{l}\text { Follow-up } \\
\text { median } \\
\text { (range) }\end{array}$ & $n$ \\
\hline \multicolumn{4}{|l|}{ Section 1. Bases of practice knowledge } \\
\hline 18. (19). Articles published in research journals & $3(1-5)$ & $3(1-5)$ & 194 \\
\hline \multicolumn{4}{|l|}{ Section 2. Barriers to finding and reviewing evidence } \\
\hline 22. I do not know how to find appropriate research reports & $4(1-5)$ & $4(1-5)$ & 194 \\
\hline 24. I do not have sufficient time to find research reports & $2(1-5)$ & $2(1-5)$ & 193 \\
\hline 28. I find it difficult to understand research reports & $3(1-5)$ & $3(2-5)$ & 192 \\
\hline \multicolumn{4}{|l|}{ Section 5 . Self-assessment of skills } \\
\hline 42. Finding research evidence & $2(1-5)$ & $3(1-5)$ & 192 \\
\hline 46. Reviewing research evidence & $2(1-4)$ & $3(1-5)$ & 191 \\
\hline 48. Using research evidence to change practice & $2(1-4)$ & $2(1-4)$ & 192 \\
\hline
\end{tabular}


JRIPE

6

Multi-professional intervention in EBP

Heiwe, Johansson, Nilsson-Kajermo, Säflund, \& Ödlund Olin

Journal of Research in Interprofessional Practice and Education

Vol. 3.2

August, 2013
Journal of Research in Interprofessional Practice and Education

The GEE analysis resulted in the following predictive models (Table 3):

Table 3

\section{Main findings from the General Equation Estimation analysis (GEE)}

\begin{tabular}{|c|c|c|c|}
\hline Model Finding research evidence & OR & $95 \%$ C.I & $p$ \\
\hline Main effect of educational intervention & 3.6 & $1.75-7.48$ & 0.0005 \\
\hline \multicolumn{4}{|c|}{ Interaction "Baseline rating" Knowing how to find appropriate research reports'X Time } \\
\hline Limited experience & 24.20 & $9.11-64.36$ & $<0.0001$ \\
\hline Experience prior to course & 0.54 & $0.20-1.43$ & 0.21 \\
\hline \multicolumn{4}{|l|}{ Interaction "understanding of language in reports" X Time } \\
\hline Not understanding & 1.37 & $0.51-3.70$ & 0.54 \\
\hline Understanding & 4.82 & $1.65-14.11$ & 0.004 \\
\hline Baseline rating "finding research evidence" & 2.18 & $1.41-3.39$ & 0.0005 \\
\hline Model Reviewing research evidence & OR & $95 \%$ C.I & $p$ \\
\hline Main effect of educational intervention & 2.18 & $1.41-3.39$ & 0.0005 \\
\hline \multicolumn{4}{|c|}{ Interaction "knowing how to find appropriate research reports" $X$ Time } \\
\hline Knowing & 7.1 & $3.81-13.05$ & $<0.0001$ \\
\hline Not knowing & 0.33 & $0.17-0.65$ & 0.001 \\
\hline \multicolumn{4}{|l|}{ Interaction "understanding of language in reports" $\mathrm{X}$ Time } \\
\hline Understand & 0.43 & $0.21-0.85$ & 0.02 \\
\hline Do not understand & 0.53 & $0.30-0.96$ & 0.04 \\
\hline \multicolumn{4}{|l|}{ Interaction "capacity to reviewing evidence" X Time } \\
\hline Limited ability & 7.1 & $3.8-13.1$ & $<0.0001$ \\
\hline High ability & 0.68 & $0.36-1.27$ & 0.023 \\
\hline \multicolumn{4}{|l|}{ Academic degree } \\
\hline Bachelor/Master/PhD & 1.66 & $1.02-2.71$ & 0.04 \\
\hline Less academic degree & 0.54 & $0.31-0.95$ & 0.03 \\
\hline Model Using research evidence to change practice & OR & $95 \%$ C.I & $p$ \\
\hline Main effect of educational intervention & 1.30 & $0.89-1.89$ & 0.18 \\
\hline \multicolumn{4}{|c|}{ Baseline rating "use of research reports as a basis for knowledge used within clinical practice" } \\
\hline Often/sometimes & 0.17 & $0.09-0.34$ & $<0.0001$ \\
\hline Never/seldom & 0.44 & $0.25-0.79$ & 0.006 \\
\hline \multicolumn{4}{|l|}{ Interaction "use of evidence" X Time } \\
\hline Limited use & 3.74 & $2.47-5.68$ & $<0.0001$ \\
\hline High rate of use prior to course & 0.45 & $0.24-0.84$ & 0.012 \\
\hline \multicolumn{4}{|l|}{ Academic degree } \\
\hline Bachelor/Master/PhD & 1.66 & $1.02-2.71$ & 0.04 \\
\hline Less academic degree & 0.54 & $0.31-0.95$ & 0.03 \\
\hline \multicolumn{4}{|l|}{ Profession } \\
\hline Nurse & 1.97 & $1.20-3.23$ & 0.007 \\
\hline Other & 0.85 & $0.50-1.45$ & 0.55 \\
\hline
\end{tabular}


7

Multi-professional intervention in EBP

Heiwe, Johansson, Nilsson-Kajermo, Säflund, \& Ödlund Olin

Journal of Research in Interprofessional Practice and Education

Vol. 3.2

August, 2013

\section{Finding research evidence}

The capacity at baseline for knowing how to find appropriate research reports (item 22), time available to find the reports (item 24), understanding of the language in the reports (item 28), as well as level of academic degree and change-over-time were shown to be independent factors that could be used in a model to predict the dependent factor finding research evidence (item 42). The main effect of the educational intervention was an overall odds ratio (OR) of 3.6, $p=.0005,95 \%$ CI $[1.75$, 7.48]. The GEE analyses also showed statistically significant interaction between the independent factor time (before versus after the educational intervention), baseline capacity for knowing how to find appropriate research reports (item 22; $p=.042$ ), and baseline understanding of the language in the reports (item $28 ; p=.015$ ). This shows that the educational intervention increased the capacity to find research evidence among those who at baseline had limited experience (OR $=24, \mathrm{p}<.0001,95 \%$ CI $[9,64])$, whereas the educational intervention had no effect on those with experience prior to the course $(\mathrm{OR}=0.54, p=.21,95 \% \mathrm{CI}[0.27,1.43])$.

\section{Reviewing research evidence}

The change in capacity to review research evidence (item 46 ) could be predicted by the baseline ratings of knowing how to find appropriate research reports (item 22), understanding the language in the reports (item 28), time (before-after educational intervention), and the negvariable level of academic degree. The overall effect of the educational intervention was OR 2.18 ( $p=.0005,95 \%$ CI $[1.41,3.39])$ A significant interaction effect was found between the independent factors time and experience in reviewing research evidence (item 46 ) before participating in the course. This showed that the educational intervention had beneficial effects on those with limited ability to review research evidence at baseline $(\mathrm{OR}=7.1, p<.0001,95 \% \mathrm{CI}[3.8,13.1])$.

\section{Using research evidence to change practice}

The educational intervention's effect on the use of research evidence in order to change clinical practice (item 48) could be predicted by a model, including the following independent factors and negvariables: the participants' baseline ratings of use of research reports as a basis for their knowledge used within clinical practice (item 18), use of research evidence prior to the educational intervention (item 48), time (before-after), level of academic degree, and profession. The educational intervention showed no overall effect on the use of research evidence within clinical practice $(\mathrm{OR}=1.30, p=.18,95 \% \mathrm{CI}[0.89,1.89])$. There was, however, an interaction showing that those who scored a limited use of evidence (item 48) at baseline significantly increased their use following the educational intervention $(\mathrm{OR}=3.74$, $p<.0001,95 \%$ CI $[2.47,5.68]$ ), whereas those who at baseline already rated a high use of research evidence in order to change clinical practice instead showed a significant decrease in rated level of use 6 months after the educational intervention $(\mathrm{OR}=0.45, p=.012,95 \% \mathrm{CI}[0.24,0.84])$. Following the educational intervention registered nurses/midwives reported a higher use $(\mathrm{OR}=1.97, p=.007,95 \% \mathrm{CI}$ 
8

Multi-professional intervention in EBP

Heiwe, Johansson, Nilsson-Kajermo, Säflund, \& Ödlund Olin

Journal of Research in Interprofessional Practice and Education

Vol. 3.2

August, 2013
$[1.20,3.23])$ of research evidence in order to change clinical practice than other professionals $(\mathrm{OR}=0.85, p=.55,95 \% \mathrm{CI}[0.50,1.45])$.

\section{Discussion}

Evidence-based practice requires that healthcare decisions are based on the best available valid and relevant evidence and integrated with the clinical experience and patients' needs. The process of evidence-based practice should therefore be a mandatory competency for all healthcare providers. The workforce performance according to evidence-based guidelines and standards could be seen as a cornerstone for the assurance of quality within the healthcare system. Healthcare providers therefore continuously need to update their knowledge and improve the healthcare provided. Various interventions are used today to improve the utilization of research evidence into clinical practice. One of these is education.

This study focused on assessing the outcome of an educational intervention. The educational intervention used in this study included an interactive teaching method that allowed flexibility for teachers and learners. This educational strategy has been shown to enhance critical thinking and analytic skills, as well as to motivate professional growth [13]. The primary outcomes of interest were the knowledge of how to find research evidence, the capacity to review research evidence, and the use of research evidence in order to change clinical practice. The educational intervention in the present study was shown to improve perceived skills in finding and reviewing evidence, and these findings were in line with the course content and aim.

Several different professions were invited and participated in the educational intervention in this study. Having a multidisciplinary focus is shown to be perceived to increase the chances of successful implementation of evidence into practice [14]. Furthermore, practice-based interprofessional interventions, for example, interprofessional rounds, interprofessional meetings, and externally facilitated interprofessional audits, can lead to improvements in patient care [1]. Although not explored in the current study, we assumed that a multiprofessional course would increase the awareness of the necessity of interprofessional collaboration and encourage subsequent team building in applying the entire process of evidence-based practice.

The type of educational intervention used in the present study has also been used in previous research aimed at increasing the use of evidence-based practice among healthcare providers. Kim et al. have, for instance, shown that the effectiveness of this type of intervention resulted in a significantly higher level of knowledge and use of evidence-based practice $[15,16]$, with a main effect size of $8 \%$ and $5 \%$, respectively. In the present study, the participants also improved their knowledge, but not their overall use of research evidence. An interactive and clinically integrated teaching strategy was chosen in the present study because this type of teaching, in contrast with lecture-based teaching, has also been found to affect attitudes and have an effect within multiple professions $[7,17,18]$.

The dependent factor that was most affected by the educational intervention was the ability to find evidence (item 42 , overall effect: $\mathrm{OR}=3.6,95 \%$ CI $[1.75,7.48]$ ). Having limited experience finding research evidence prior to the educational inter- 
9

Multi-professional intervention in EBP

Heiwe, Johansson, Nilsson-Kajermo, Säflund, \& Ödlund Olin

Journal of Research in Interprofessional Practice and Education

Vol. 3.2

August, 2013 vention increased the odds of improving one's capacity to find research evidence more than among those who already had experience. The scoring of use of research evidence six months following the intervention did not improve on a group level. However, limited use of research evidence prior to the educational intervention increased the odds of improving one's use of research evidence to change practice more than among those who already reported high use. It is possible that the participants would have needed to be exposed to this intervention over a longer period of time in order to achieve a larger effect size. Maybe healthcare providers need to be provided with continuous reinforcing education in order to strengthen, and maintain, the effect of the educational intervention, as well as to change their actual behaviour [19]. However, it may also be that the educational intervention on its own was not enough to increase the utilization of research findings within clinical practice, particularly among those who were more experienced in evidence-based practice before participating in the course. Increased knowledge and self-assessed use of research evidence has been found in other research studies [17,19-22], and they have also shown that although the effect of the education is significant, the magnitude of the effect is small.

Perhaps the teaching of various evidence-based practice steps needs to be integrated in everyday clinical practice by specially educated trainers in order to increase the magnitude of effect on clinical utilization of research findings [23]. Methods other than educational interventions (e.g., reminder systems) should also be considered in order to increase the use of research evidence, especially as various educational models, including the present model, have been shown to improve knowledge and reviewing skills but have little or no effect on the actual use of research evidence [4].

Future research needs to explore which methods most effectively increase knowledge, skills, and behaviours toward evidence-based practice, but, more importantly, it needs to explore which factors can modify the effectiveness of educational interventions concerning clinical research utilization. Future research focusing on evaluating the effects of interventions within this topic should be randomized controlled trials where actual knowledge, contextual factors, behaviour, and patient outcomes are registered.

A strength of the present study was the high response rate and low rate of attrition $(26.5 \%)$ six months after the course. Limitations were that the study was not designed to evaluate the impact that the educational intervention had on actual patient outcomes. Also, when using self-reports there is always a risk of overestimation, so the participants may have overrated their actual knowledge post-intervention. Further, in a one-group pretest-posttest design, a difference in data cannot unequivocally be attributed to the intervention. As there was no control group, there could be threats to the internal validity [24]. However, there was no historical event related to the dependent variables during the study period. Maturation is a possible confounder; however, this factor is always a possible confounder when using time series and is also part of the aim of an educational intervention. 
Multi-professional intervention in EBP

Heiwe, Johansson, Nilsson-Kajermo, Säflund, \& Ödlund Olin

Journal of Research in Interprofessional Practice and Education

Vol. 3.2

August, 2013

\section{Conclusion}

The findings show that the educational intervention had a significant effect on perceived ability to find and review research evidence, but there was no overall significant effect on using research evidence within clinical practice. However, subgroups showed significant improvement over time, for example, nurses and midwives and those with limited use of evidence.

\section{References}

1. Sackett, D.L., Rosenberg, W.M.C., Gray, J.A.M, Haynes, R.B., \& Richardson, W.S. (2007). Evidence based medicine: What it is and what it isn't. 1996. Clinical Orthopaedics and Related Research, 455, 3-5.

2. Straus, S.E., Ball, C., Balcombe, N., Sheldon, J., \& McAlister, F.A. (2005). Teaching evidence-based medicine skills can change practice in a community hospital. Journal of General Internal Medicine, 20(4), p. 340-343.

3. Fritsche, L., Greenhalgh, T., Falck-Ytter, Y., Neumayer, H-H., \& Kunz, R. (2002). Do short courses in evidence based medicine improve knowledge and skills? Validation of Berlin questionnaire and before and after study of courses in evidence based medicine. British Medical Journal, 325(7376), 1338-1341.

4. McCluskey, A., \& M. Lovarini, M. (2005). Providing education on evidence-based practice improved knowledge but did not change behaviour: A before and after study. BMC Medical Education, 5, 40.

5. Taylor, C.B., \& Curry, S.J. (2004). Implementation of evidence-based tobacco use cessation guidelines in managed care organizations. Annals of Behavioral Medicine, 27(1), 13-21.

6. Parkes, J. (2001). Teaching critical appraisal skills in health care settings. Cochrane Database of Systematic Reviews, 3, CD001270.

7. Coomarasamy, A., \& Khan, K.S. (2004). What is the evidence that postgraduate teaching in evidence based medicine changes anything? A systematic review. British Medical Journal, 329(7473), 1017.

8. Grol, R. (2002). Changing physicians' competence and performance: Finding the balance between the individual and the organization. Journal of Continuing Education in the Health Professions, 22(4), 244-51.

9. Sargeant, J. (2009). Theories to aid understanding and implementation of interprofessional education. Journal of Continuing Education in the Health Professions, 29(3), 178-184.

10. Thistlethwaite, J. (2012). Interprofessional education: A review of context, learning and the research agenda. Medical Education. 46(1), 58-70.

11. Gerrish, K., Ashworth, P., Lacey, A., Bailey, J., Cooke, J., Kendall, S., \& McNeilly, E. (2007). Factors influencing the development of evidence-based practice: a research tool. Journal of Advanced Nursing, 57(3), 328-338.

12. Cortina, J. (1993). What is Coefficient Alpha? An examination of Theory and Applications. Journal of Applied Psychology, 78, 98-104.

13. Flanagan, N.A., \& McCausland, L. (2007). Teaching around the cycle: Strategies for teaching theory to undergraduate nursing students. Nursing Education Perspectives, 28(6), 310-314.

14. Rycroft-Malone, J., Harvey, G., Seers, K., Kitson, A., McCormack, B., \& Titchen, A. (2004). An exploration of the factors that influence the implementation of evidence into practice. Journal of Clinical Nursing, 13(8), 913-924.

15. Kim, S.C., Brown, C.E., Fields, W., \& Stichler, J.F. (2009). Evidence-based practice-focused interactive teaching strategy: A controlled study. Journal of Advanced Nursing, 65(6), 1218-1227.

16. Schilling, K., Wiecha, J., Polineni, D., \& Khalil, S. (2006). An interactive web-based curriculum on evidence-based medicine: design and effectiveness. Family Medicine, 38(2), 126-132.

17. Hadley, J., Kulier, R., Zamora, J., Coppus, S.F.P.L., Weinbrenner, S., Meyerrose, B.,Decsi, T., Horvath, A.R., Nagy, E., Emparanza, J.I., Arvanitis, T.N., Burls, A., Cabello, J.B. Kaczor, M., Zanrei, G., Pierer, K., Kunz, R., Wilkie, V., Wall, D., Mol, B.W.J., \& Khan, K.S. (2010). Effectiveness of an e-learning course in evidence-based medicine for foundation (internship) training. Journal of the Royal Society of Medicine, 103(7), 288-294.

18. Khan, J.D., \& C. Sennett. (2004). The role of evidence-based medicine. AHIP Cover, 45(6), 16-20.

19. Shuval, K., Shachak, A., Linn, S., Brezis, M., Feder-Bubis, P., \& Reis, S. (2007). The impact of an evidence-based medicine educational intervention on primary care physicians: A qualitative study. Journal of General Internal Medicine, 22(3), 327-331. 
11

Multi-professional intervention in EBP

Heiwe, Johansson, Nilsson-Kajermo, Säflund, \& Ödlund Olin
20. Kulier, R., Coppus, S.F., Zamora, J., Hadley, J., Malick, S., Das, K., Weinbrenner, S., Meyerrose, B., Decsi, T., Horvath, A.R., Nagy, E., Emparanza, J.I., Arvanitis, T.N., Burls, A., Cabello, J.B., Kaczor, M., Zanrei, G., Pierer, K., Stawiarz, K., Kunz, R., Mol, B.W., \& Khan, K.S. (2009). The effectiveness of a clinically integrated e-learning course in evidence-based medicine: A cluster randomised controlled trial. BMC Medical Education, 9, 21.

21. Kulier, R., Hadley, J. Weinbrenner, S., Meyerrose, B., Decsi, T., Horvath, A.R., Nagy, E., Emparanza, J.I., Coppus, S.F.P.J., Arvanitis., T.N., Buris, A., Cabello, J.B., Kaczor, M., Zanrei, G., Pierer, K., Stawiarz, K., Kunz, R., Mol, B.W.J., \& Khan, K.S. (2008). Harmonising evidence-based medicine teaching: A study of the outcomes of e-learning in five European countries. BMC Medical Education, 8, 27.

22. Kulier, R., Khan, K.S., Gulmezoglu, A.M., Carroli, G., Cecatti, J.G., Germar, M.J., Lumbiganon, P., Mittal, S., Pattinson, R., Wolomby-Molondo, J-J., Bergh, A-M., \& May, W. (2010). A cluster randomized controlled trial to evaluate the effectiveness of the clinically integrated RHL evidence -based medicine course. Reproductive Health, 7, 8.

23. Thangaratinam, S., Barnfield, G., Weinbrenner, S., Meyerrose, B., Arvanitis, T.N., Horvath, A.R., Gianni Zanrei, Regina Kunz, Katja Suter, Jacek Walczak, Kaleta, A., Rengerink, K.O., Gee, H., Mol, B.W.J., \& Khan, K.S. (2009). Teaching trainers to incorporate evidence-based medicine (EBM) teaching in clinical practice: The EU-EBM project. BMC Medical Education, 9, 59.

24. Schlosser, R.W. (2003). The Efficacy of Augmentative and Alternative Communication: Towards Evidence-Based Practice. Emerald Group Publishing Limited. 